\title{
An evaluation of changes to protein supply in Zambia between 1961 and 2013 shows consistent dominance of plant-based sources
}

\author{
N.P. Kapulu ${ }^{1}$, H. Clark ${ }^{2}$, C. Orfila ${ }^{1}$ and J.I. Macdiarmid ${ }^{2}$ \\ ${ }^{1}$ Nutritional Sciences and Epidemiology, School of Food Science and Nutrition, University of Leeds, Leeds, LS2 9JT \\ and \\ ${ }^{2}$ Rowett Institute, University of Aberdeen, Aberdeen, AB25 2ZD, United Kingdom
}

Dietary protein is essential to maintain optimum growth and maintenance of body muscles in humans ${ }^{(1)}$. Although animal sources of protein have a higher biological value and protein digestibility than most foods ${ }^{(2)}$, they are beyond the economic reach of many, especially those living in the global south. However, protein from animal sources is environmentally unsustainable, and excess consumption of red and processed meats are associated with increased risk of non-communicable diseases ${ }^{\text {(3) }}$. Using Zambia as a case study, this study aimed to assess the supply of protein from various food sources to meet population-level requirements, including changes that have occurred over time.

A list of 264 food items for 13 commodity groups in the FAO food balance sheets was developed using information from the FAO handbook and local knowledge of commonly consumed foods. The protein content for each item was estimated from West African food composition tables and where the food was not in these tables data from United States Department of Agriculture composition tables were used. The primary sources of protein and supply trends to meet age-and-gender specific population-level nutrition requirements for the period 1961-2013, were assessed.

The results showed that in Zambia, $74 \%$ of the protein was supplied from plant-based sources, including cereals (62\%), oil crops $(5 \%)$, starchy roots $(3 \%)$, vegetables $(2 \%)$ and pulses $(2 \%)$, while about $24 \%$ came from animal foods comprising meat $(17 \%)$, fish $(4 \%)$, dairy $(2 \%)$, and eggs $(1 \%)$. Zambia was able to meet the protein population requirements from plant-based sources alone sufficiently. Although the supply of protein from 1961-2013 exceeded population-level nutrient requirements, its availability gradually declined from about $76 \mathrm{~g} / \mathrm{capita} /$ day to approximately $63 \mathrm{~g} / \mathrm{capita} / \mathrm{day}$. Total protein supply, especially between the late $1970 \mathrm{~s}$ and early 2000 was affected by a decline in supply from cereals and oil crops, which may be due to reduced wheat imports, maize and groundnut production, respectively. Beyond 2005, contributions to total protein from oil crops improved exponentially because of increased soybean production, while amounts from animal sources were notably unchanged between 1961 and 2013 . The trend in protein supply follows the same pattern in the total energy supply.

This study shows that population-level nutritional requirements for total protein is adequate and can be met from plant-based sources in developing countries where animal source foods are unaffordable for the majority of poor people. However, the diversity of diets and food sources needs to increase to ensure the quality of the protein is sufficient and nutrition security can be achieved. Dietary changes to achieve this must be carefully considered so as not to create a negative impact on health and the envrionment.

1. Bauer J, Biolo G, Cederholm T et al. (2013) J Am Med Dir Assoc 14, 542-559.

2. Hoffman JR \& Falvo MJ (2004) J Sports Sci Med 3, 118-130.

3. Nijdam D, Rood T \& Westhoek H (2012) Food Policy 37, 760-770. 